\title{
ORIGEM DOS MEGACRISTAIS DE K-FELDSPATO DO GRANITO DE MONTE DAS GAMELEIRAS, RIO GRANDE DO NORTE/PARAÍBA, BRASIL
}

\author{
ANTÔNIO CARLOS GALINDO*
}

\begin{abstract}
ORIGIN OF K-FELDSPAR MEGACRYSTS FROM MONTE DAS GAMELEIRAS GRANITE, RIO GRANDE DO NORTE/PARAÍBA, BRAZIL. The Monte das Gameleiras granitic batholith is located at the boundary between Rio Grande do Norte and Paraíba States in northeastern Brazil. Two main types of granitic rocks have been identified in this batholith. Dioritic inclusions occur in both of them. The predominating type is an extremely porphyritic syenogranite, which is intruded by a fine-grained monzogranite. $\mathrm{K}$-feldspar megacrysts are found in both porphyritic granite and dioritic inclusions. The megacrysts long axes average around $4 \mathrm{~cm}$, reaching up to 9 or $10 \mathrm{~cm}$. The megacrysts are euhedral, zoned, and, sometimes, they show rapakivi texture. Flow textures and tuillage are common, but irregularly distributed. The $\mathrm{K}$-feldspar megacrysts contain inclusions of plagioclase, biotite, quartz, hornblende, sphene, and apatite. These inclusions are concentrically arranged and parallel to the megacrysts zones. The included minerals are generally smaller than the same minerals in the groundmass. Microprobe analyses and x-ray difraction studies show that the megacrysts of both facies are similar in composition, containing around $90 \%$ of orthoclase. Taking into account the textural and compositional aspects, it is concluded that the megacrysts of porphyritic granite and dioritic inclusions are phenocrysts and not porphyroblasts.
\end{abstract}

RESUMO O batólito granítico de Monte dos Gameleiras localiza-se na divisa interestadual entre Rio Grande do Norte e Paraíba, no Nordeste do Brasil. Dois tipos principais de rochas graníticas foram identificados no batólito. Ocorrem intrusōes dioríticas em ambos os tipos. O tipo predominante é um sienogranito extremamente porfirítico, que é penetrado por um monzogranito fino. Megacristais de $\mathrm{K}$-feldspato estão presentes tanto no granito como nas inclusôes dioríticas. Os eixos maiores dos megacristais possuem em média $4 \mathrm{~cm}$, atingindo até $9 \mathrm{ou} 10 \mathrm{~cm}$. São megacristais euedrais, zonados e que às vezes, mostram textura rapakivi. Texturas de fluxo e de entelhamento (tuillage) são comuns, embora irregularmente distribuídas. Os megacristais de K-feldspato contêm inclusôes de plagioclásio, biotita, quartzo, horblenda, titanita e apatita. As inclusões são concêntricamente dispostas e paralelas ao zoneamento dos megacristais. Os minerais de inclusão são geralmente menores que os mesmos minerais da massa. Análises nos microssonda e estudos por difração de raios-X mostram que os megacristais de ambos os fácies possuem composição similar, contendo cerca de $90 \%$ de ortoclásio. Levando-se em conta os aspectos composicionais e texturais, concluiu-se que os megacristais do granito portirítico e das inclusōes dioríticas são fenocristais e não porfiroblastos.

\section{INTRODUÇÃO}

O granitóide de Monte das Gameleiras constitui um batólito de aproximadamente $350 \mathrm{~km}^{2}$, localizado no extremo sudeste do Rio Grande do Norte e extremo nordeste da Paraíba (Fig. 1). Litologicamente, sāo reconhecidos dois tipos petrográficos principais de caráter granítico, encraves diversos de composição intermediária a básica, além de veios e diques aplíticos, pegmatíticos e, mais raramente, quartzosos (Galindo 1982). O batólito está encaixado num complexo gnáissico-migmatítico, relatado em trabalhos prévios como Grupo Caicó de idade arqueana, com cerca de 2,7 Ga (Brito-Neves et al. 1976). Numa seqüência cronológica a unidade mais jovem é representada por um granito fino eqüigranular (monzogranito) cortando um granito porfirítico de textura grossa (sienogranito), ambos englobando encraves de rochas dioríticas.

\section{ASPECTOS MACRO E MICROSCÓPICOS DOS ME- GACRISTAIS Os megacristais do granitóide de Monte} das Gameleiras apresentam dimensões médias da ordem de 4,0 $\mathrm{cm}$ segundo seu eixo maior de alongamento, podendo atingir por vezes até mais de 9,0. São cristais essencialmente euédricos zonados (Figs. 2 e 3), apresentando inclusōes de biotita e/ou hornblenda, quartzo e plagioclásio (em amostra de mão), mostrando localmente textura tipo rapakivi. Os megacristais ocorrem tanto no granito porfirítico quanto nos encraves dioríticos, apresentando em ambos os casos os mesmos aspectos texturais (Fig. 4). A proporção e o tamanho dos megacristais aumentam das bordas para o centro do corpo e, localmente, estes desenvolvem textura de cumulados conferindo à rocha uma composição de álcali-feldspato sienito (Fig. 5).
O granitóide apresenta uma foliação penetrativa, mais marcante nas bordas do corpo, envolvendo a orientação dos máficos (biotita e anfibólio) e, em menor grau, dos megacristais de $\mathrm{K}$-feldspato e encraves dioríticos. Esta foliação está sendo interpretada como a conjugação dos efeitos de baloneamento associados à colocaçẫo do corpo (efeito balooning)

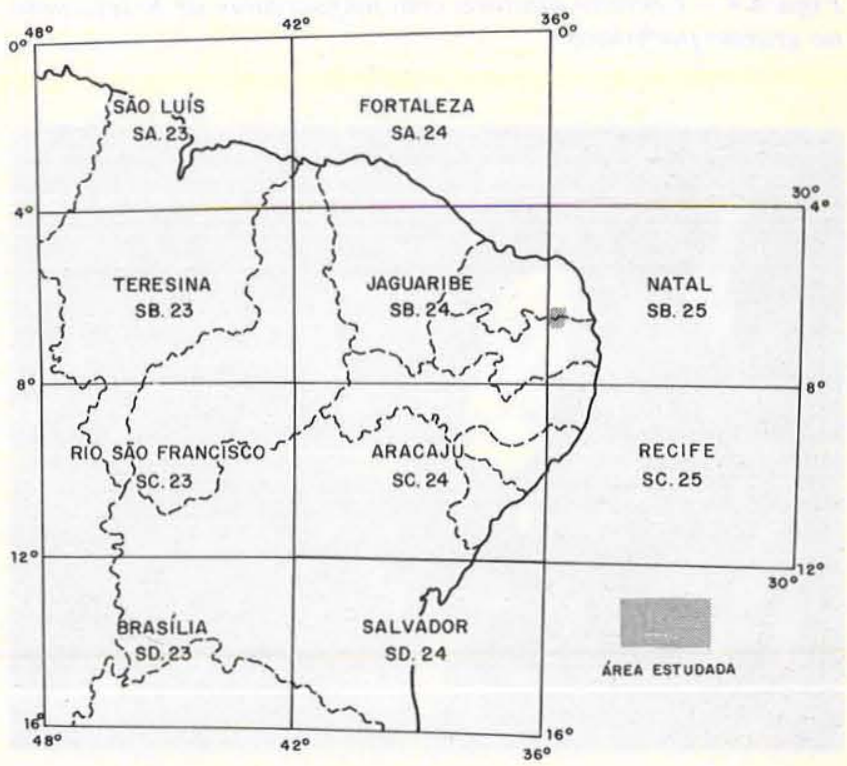

Figura 1 - Localização da área estudada 


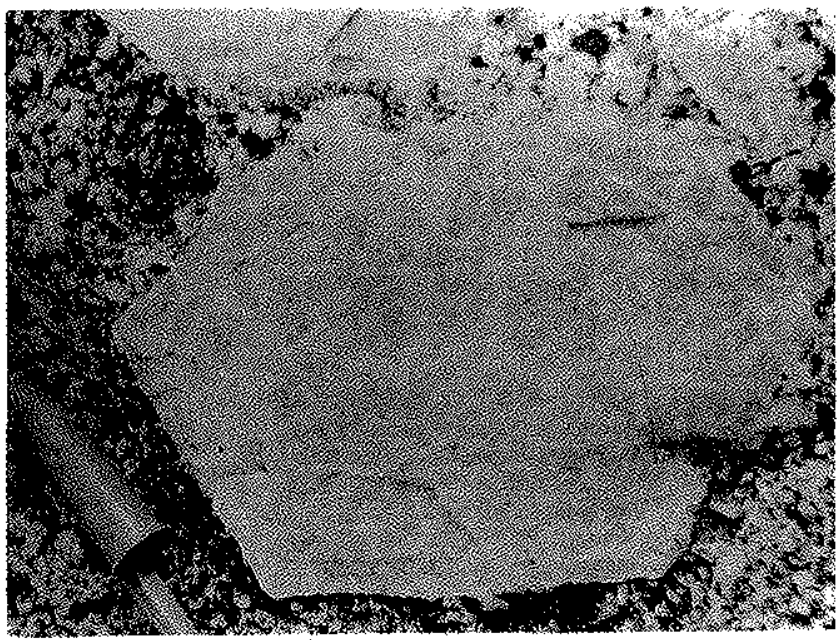

Figura 2 - Megacristal euédrico e zonado de K-feldspato no granito porfiritico

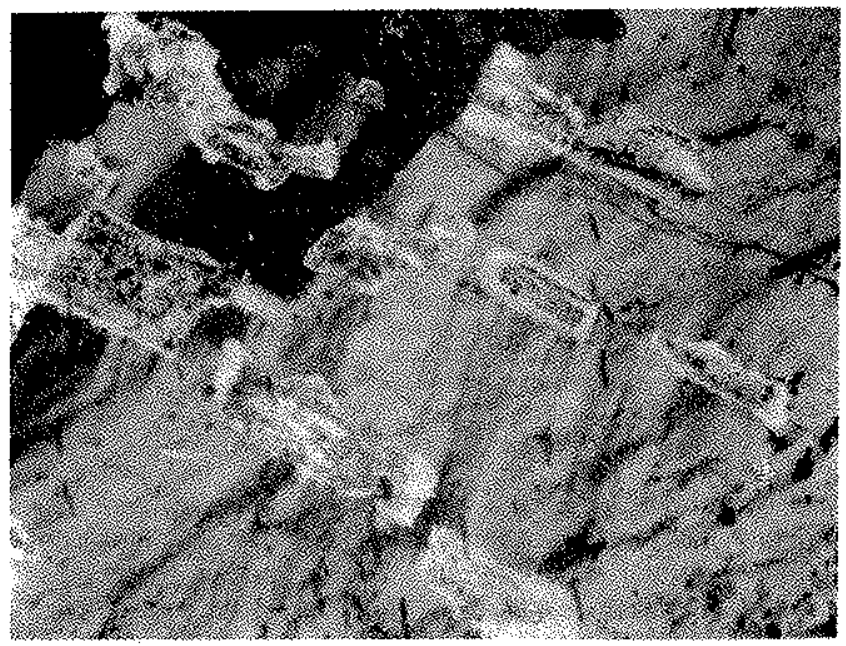

Figura 4 - Encrave dioritico com megacristais de $K$-feldspato no granito porfiritico

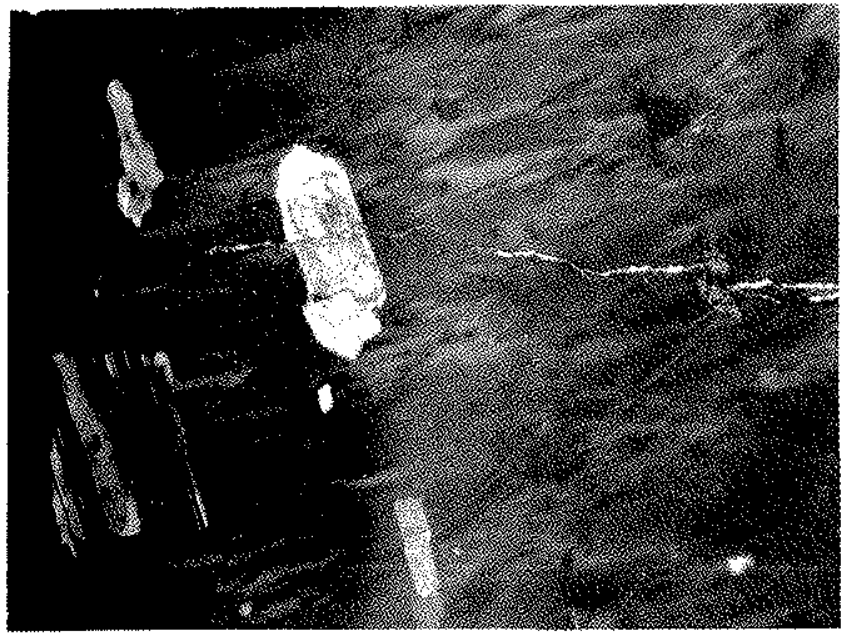

Figura 6 - Megacristal de K-feldspato com inclusöes orientadas de plagioclásio (nicóis cruzados; aumento linear 54 vezes)

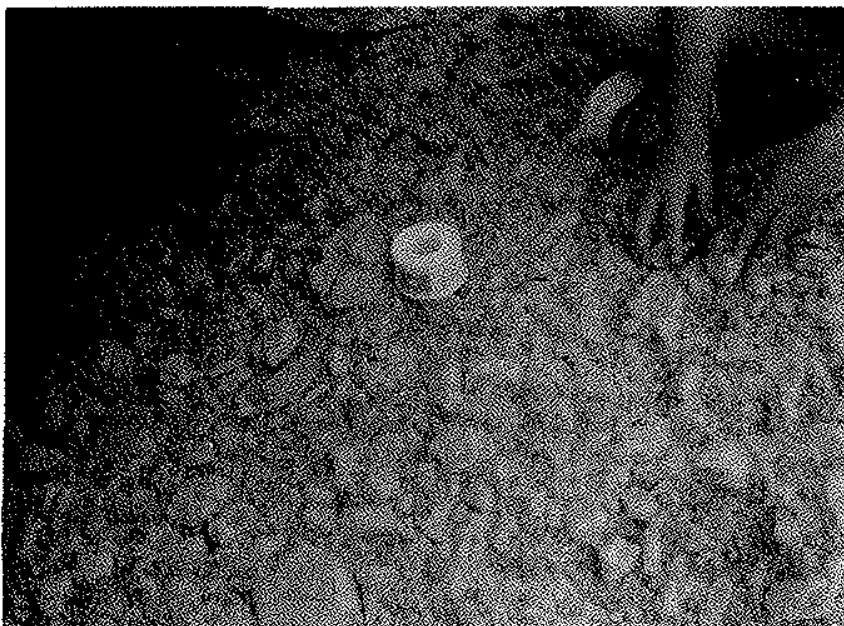

Figura 3 - Aspecto geral da textura do granito porfíritico na região central do granitóide

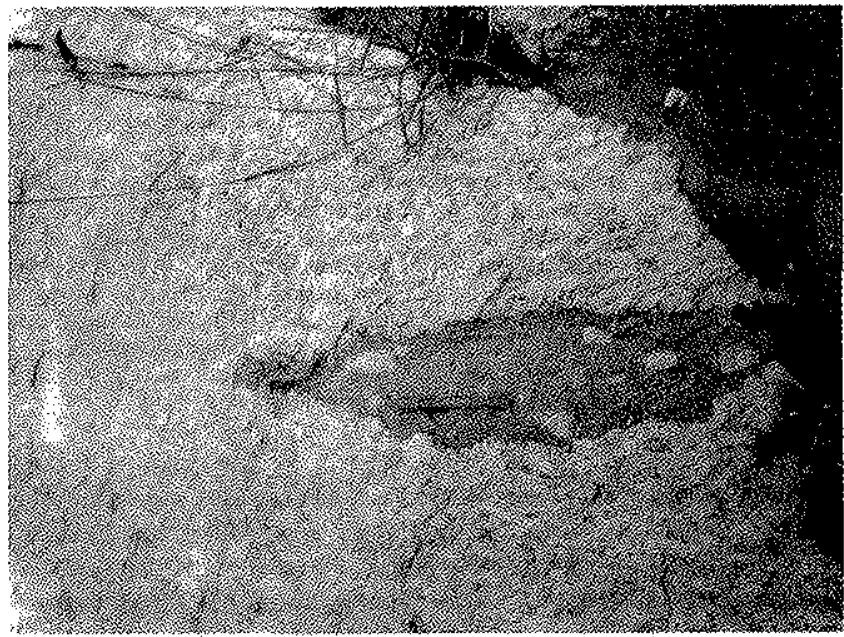

Figura 5 - Textura de cumulado de K-feldspato no granito porfiritico

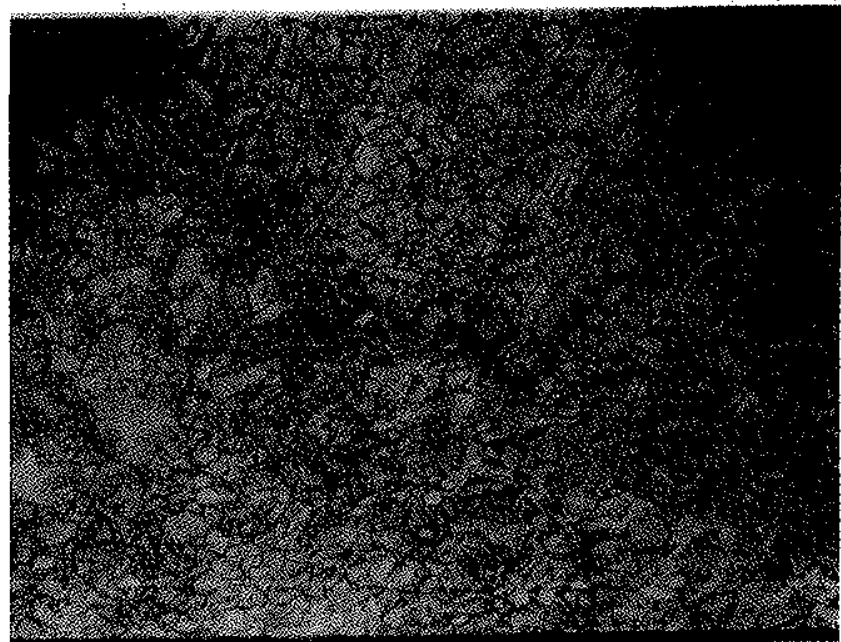

Figura 7 - Inclusōes orientadas de plagioclásio e titanita (à direita da foto) num megacristal de $K$-feldspato do granito porffritico (nicóis cruzados; aumento linear 54 vezes) 
com aqueles causados pela tectônica regional, relacionada ao Ciclo Brasiliano, que teve atuação destacada na região do Seridó (Galindo et al. 1987). Localmente, os megacristais apresentam orientações divergentes em relação à foliação dominante no corpo, sendo as primeiras interpretadas como texturas de fluxo. Texturas de entelhamento (tipo tuillage) também são eventualmente observadas.

Ao microscópio, os megacristais são geralmente subédricos, com bordas irregulares, associando-se a elas textura tipo mortar. Mirmequita se apresenta na forma de bolhas dentro do $\mathrm{K}$-feldspato e também nas interfaces de contato plagioclásio/feldspato potássico. A zonação comum em amostra de mão por vezes nāo é bem visível em lâmina, sendo entretanto marcada pelo arranjo das inclusōes, notadamente as de plagioclásio. Os megacristais mostram comumente a conjugação das geminações Carlsbad e albita-periclínia (microclinização do ortoclásio?). Pertitização ocorre com mais freqüência nas partes centrais dos megacristais, sendo as pertitas dos tipos stringlets $e$ strings (pertitas finas) predominantes (classificação de Alling 1938 apud Deer et al. 1976).

À escala microscópica observam-se inclusões variadas nos megacristais, sendo plagioclásio, quartzo, biotita, hornblenda, titanita e apatita as principais e, secundariamente, opacos e zircảo. O plagioclásio constitui em média de $90 \%$ a $95 \%$ das inclusōes. Apresenta-se em pequenos cristais, via de regra subédricos e, por vezes, euédricos, geralmente orientados com seu eixo maior paralelo às faces do megacristal. Seus núcleos são comumente saussuritizados (epidotização essencialmente), enquanto as bordas são mais preservadas (Figs. 6 e 7). Este aspecto deve refletir uma variação composicional sendo os núcleos primitivos mais cálcicos e as bordas mais sódicas. $\mathrm{O}$ teor de anortita das inclusões varia de $23 \%$ a $28 \%$ (determinado pelo método de Michel-Lévy com o auxílio da platina universal), sendo que as mais externas ao megacristal apresentam teores sempre menores que as mais internas. Os plagioclásios da matriz, por sua vez, apresentam anortita variando de $18 \%$ a $24 \%$, ou seja, teores compatíveis com os observados nas inclusôes mais externas.

O quartzo $\hat{e}$, depois do plagioclásio, a principal inclusão. Ocorre em cristais essencialmente anédricos e menores que os de plagioclásio. Biotita, titanita, hornblenda, apatita, opacos e zircão formam sempre cristais subédricos a euédricos, pequenos, e não somam $5 \%$ das inclusões.

ANÁLISES POR MICROSSONDA Os dados de composição dos feldspatos potássicos apresentados na Tabela 1 são de McMurry (1982). Eles foram obtidos em três amostras do granito porfirítico, nas quais a autora citada analisou um megacristal e um grão de microclínio da matriz. Em todos os casos foram analisados os elementos maiores e os teores de bário e em dois deles (amostras GA-15a e GA-18b) foram também feitas travessas para verificar um possível zoneamento do bário. Diante dos resultados obtidos chega-se às seguintes conclusōes: a. os teores dos elementos maiores praticamente não mostram variações nos diversos megacristais, nem mesmo entre estes e os microclínios da matriz; b. as travessas para bário (Figs. 8 e 9) mostram uma zonação nos megacristais (ainda que não seja muito expressiva), sendo os núcleos mais enriquecidos em bário do que as bordas. Nota-se ainda novo aumento nos teores de bário nas partes mais externas do megacristal, na passagem da borda para a coroa (regiâo de contato megacristal-matriz); c. os teores de bário da matriz são similares aos das partes mais externas do megacristal (coroas), indicando uma provável condição de cristalização em equilibrio entre a matriz e as bordas externas dos megacristais.

ANÁLISES POR DIFRAÇÃO DE RAIOS-X Análises de difração de raios- $X$ realizadas em laboratório da Universidade Federal de Pernambuco resultaram na obtenção de 21 difratogramas: oito de megacristais do granito porfíritico, dois
Tabela 1 - Análises de microssonda de megacristais e microclínios da matriz do granito porfirítico (segundo McMurry 1982)

\begin{tabular}{|c|c|c|c|c|c|c|}
\hline \multirow{2}{*}{$\begin{array}{l}\text { Amos- } \\
\text { tras }\end{array}$} & \multicolumn{2}{|c|}{ GA-05 } & \multicolumn{2}{|c|}{ GA-15a } & \multicolumn{2}{|c|}{ GA-18b } \\
\hline & 1 & 2 & 3 & 4 & 5 & 6 \\
\hline $\mathrm{SiO}_{2}$ & 63,34 & 63,54 & 65,03 & 64,78 & 65,17 & 64,70 \\
\hline $\mathrm{Al}_{2} \mathrm{O}_{3}$ & 18,25 & 18,34 & 18,25 & 18,62 & 18,49 & 18,23 \\
\hline $\mathrm{CaO}$ & 0,11 & 0,11 & 0,00 & 0,00 & 0,00 & 0,27 \\
\hline $\mathrm{Na}_{2} \mathrm{O}$ & 0,81 & 0,67 & 0,92 & 0,82 & 0,79 & 0,49 \\
\hline $\mathrm{K}_{2} \mathrm{O}$ & 15,29 & 14,43 & 15,22 & 15,45 & 15,30 & 15,40 \\
\hline $\mathrm{BaO}$ & 0,58 & 0,57 & 0,53 & 0,66 & 0,31 & 0,34 \\
\hline Total & 99,38 & 97,67 & 99,95 & 100,33 & 100,06 & 99,42 \\
\hline Mol.\% Or & 91,10 & 91,78 & 90,74 & 91,42 & 92,21 & 93,51 \\
\hline$\overline{\mathrm{Mol} . \% \mathrm{Ab}}$ & 7,30 & 6,50 & 8,30 & 7,37 & 7,22 & 4,48 \\
\hline Mol.\% An & 0,53 & 0,60 & 0,00 & 0,00 & 0,00 & 1,37 \\
\hline
\end{tabular}

Obs.: Todas as análises são do granito porfirítico. As amostras 1,3 e 6 sảo de megacristais e as 2,4 e 5 , de microclina da matriz.

de megacristais de encraves dioríticos e um de microfenocristal da matriz do granito porfirítico. Os outros 10 difratogramas sâo de cinco amostras de megacristais do granito, nas quais se separou pó da parte central e da borda de cada um deles. As condições de trabalho do aparelho foram: radiação $\mathrm{CuK} \alpha$, velocidade do goniômetro de 1 a $1 / 4^{\circ}$ por minuto a depender de cada amostra, velocidade do papel de 20 $\mathrm{mm} / \mathrm{min}, 20 \mathrm{~mA}$ e $35 \mathrm{kV}$, escala de $4 \times 10^{2}$ e uma constante de tempo igual a 2. Toda as amostras foram homogeneizadas com quartzo na proporção $\mathrm{Kf}: \mathrm{Qz}=2: 1$. Esta medida se fez necessária para melhor fixar as posiçōes das reflexōes $\overline{2} 01$, $\overline{2} 04$ e 060 do $\mathrm{K}$-feldspato utilizadas na determinação do seu teor de ortoclásio e de seu estado estrutural pelas metodologias de Wright (1968) e Jones et al. (1969), está última só para o teor de ortoclásio. As reflexōes 102 e 112 do quartzo foram usadas, respectivamente, para a correção das posições das reflexões $\overline{2} 04$ e 060 dos K-feldspatos. Por outro lado, a posição da reflexão $\overline{2} 01$ do feldspato potássico foi corrigida utilizando-se as reflexões 100 e 101 do quartzo.

Apenas seis dos 21 difratogramas deram bons resultados para a obtenção dos parâmetros acima referidos considerando as premissas dos metódos utilizados. Nos demais não foi possível separar-se as reflexões $\overline{2} 01$ do $\mathrm{K}$-feldspato daquela 100 do quartzo, uma vez que elas tendem a se superpor. Dessa forma não se pôde calcular o teor de ortoclásio pelos métodos de Wright (op. cit) e Jones et al. (op. cit.).

O estado estrutural/triclinicidade (conforme Smith 1974, vol. I, p. 218 e 287) foi determinado pelo método de Wright (op. cit.), utilizando-se as reflexões 204 e 060 dos $\mathrm{K}$-feldspatos (Tab. 2). Esta metodologia foi usada por possi-

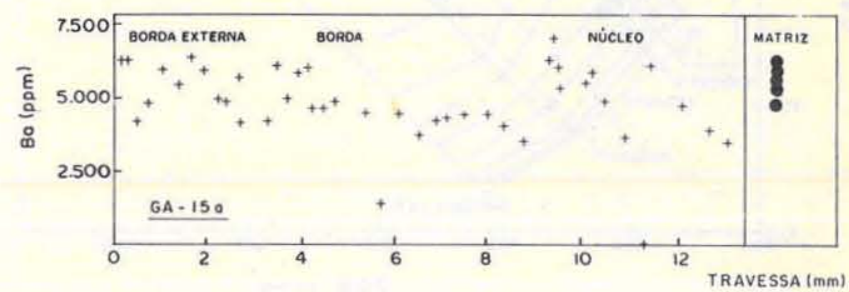

Figura 8 - Variação dos teores de bário (análises por microssonda) em megacristais do granito porfirítico (segundo McMurry 1982) 


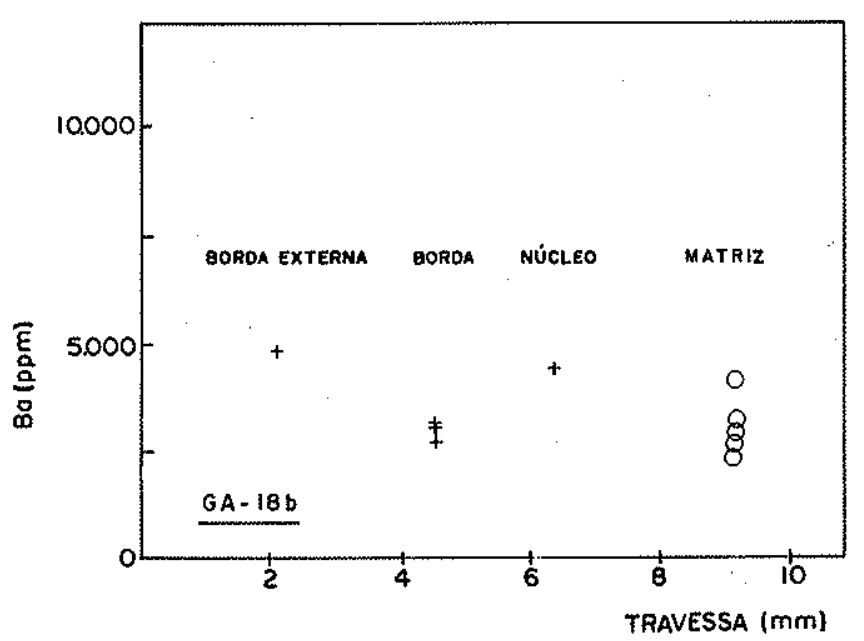

Figura 9 - Variação dos teores de bário (análises por micros" sonda) em megacristais do granito porfirítico (segundo McMurry 1982)

bilităr a determinação do teor de ortoclásio a partir da utilização da reflexão $\overline{201}$ do feldspato potássico. A posição dos pontos no diagrama 204 x 060 (Fig. 10) indica serem os megacristais microclinio intermediario, com duas amostras situando-se entre ortoclásio e Benson (um estado estrutural mais próximo de ortoclásio), e as demais próximas de Spencer- $U$ ou entre Spencer- $U$ e microclínio máximo-albita baixa (mais condizente com estado estrutural triclínico).

A partir do diagrama de estado estrutural (Fig. 10) e dos dados da reflexão 201 (Tab. 2), verifica-se que todos os megacristais são caracterizados como feldspatos anômalos (as dimensões de suas cela unitárias não sáo normais). Segundo Wright (op. cit.), isto ocorre quando a diferença entre as reflexōes $\mathbf{2 0 1}$ medidas nos difratogramas e a estimada pelo diagrama estado estrutural, para cada megacristal separadamente, é maior do que $0,1^{\circ}$ de $2 \theta$. Nestes casos, este autor não recomenda o uso da reflexão $\overline{2} 01$ para calcular o teor de ortoclásio dos feldspatos potássicos. Por outro lado, o mesmo autor menciona que, mesmo feldspatos anômalos estrutural-

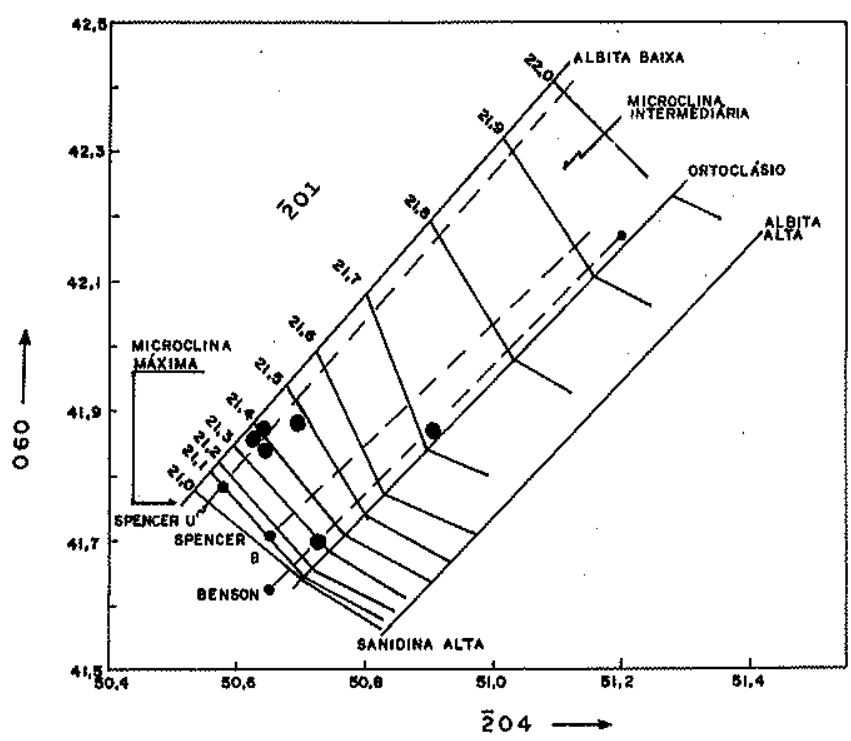

Figura 10 - Estado estrutural dos $K$-feldspato (adaptado de Wright 1968) mente podem ter seus teores de ortoclásio determinados desde que se conheçam os parámetros, $a, b, c$ de suas celas unitárias. A partir deles se determinam os volumes das celas e se utilizam os valores encontrados na figura la de Wright \& Stewart (1968).

Tabela 2 - Dados de analises de difração de raios- $X$ de megacristais de $K$-feldspato para a determinação do estado estrutural

\begin{tabular}{c|c|c|c|c|c|c}
$\begin{array}{c}\text { Refe- Amos- } \\
\text { tras } \\
\text { rencia }\end{array}$ & CG-02 & GA-05 & CG-29 & CG-53 & CG-60 & CG-53, \\
\hline$\overline{2} 04$ & 50,65 & 50,63 & 50,63 & 50,70 & 50,91 & 50,73 \\
060 & 41,84 & 41,87 & 41,86 & 41,88 & 41,87 & 41,70 \\
$\overline{2} 01$ & 21,03 & 21,03 & 20,99 & 21,05 & 21,00 & 21,07 \\
\hline
\end{tabular}

Obs.: Amostras CG-02, GA-05, CG-29, CG-53 e CG-60 são do granito; $\mathrm{CG} 553$ ' é megacristal de encrave diorítico

Apesar das restrições quanto à utilizaçăo da reflexão $\overline{201}$, foram lançados os valores das mesmas, calculados a partir dos vários difratogramas, nos diagramas de Wright (op. cit.) e Jones et al. (op. cit.), para se ter uma idéia das composiçóes (Figs. 10 e 11), ainda que aproximadas, e poder compará-las com os dados disponíveis de microssonda (Tab. 1). Os dados da reflexão $\overline{2} 01$ usados nesta determinaçăo, bem como os relativos aos parâmetros $a, b, c$ e os volumes das celas unitárias, encontram-se na tabela 3 .

Tabela 3 - Analises por difração de raios $X$ de magacristais de $K$-feldspato para a determinação do teor de ortoclásio

\begin{tabular}{c|c|c|c|c|c|c}
\hline $\begin{array}{c}\text { Refe- Amos- tras } \\
\text { rencia }\end{array}$ & CG-02 & GA-05 & CG-29 & CG-53 & CG-60 & CG-53' \\
\hline $\begin{array}{c}\text { 201 } \\
\text { (K-feldsp.) }\end{array}$ & 21,03 & 21,03 & 20,99 & 21,05 & 21,00 & 21,07 \\
101 & 20,19 & 20,19 & 20,19 & 20,19 & 20,19 & 20,19 \\
$\left(\mathrm{KBrO}_{3}\right.$ & 0,84 & 0,84 & 0,80 & 0,86 & 0,81 & 0,88 \\
$\Delta 2 \Theta$ & 8,572 & 8,571 & 8,585 & 8,564 & 8,582 & 8,556 \\
$a$ & 12,948 & 12,940 & 12,943 & 12,937 & 12,940 & 12,987 \\
$b$ & 7,204 & 7,207 & 7,207 & 7,198 & 7,172 & 7,195 \\
$c$ & 718,65 & 718,42 & 719,76 & 716,77 & 715,85 & 718,57 \\
$V\left(\AA^{3}\right)$ & 7,57 \\
\hline
\end{tabular}

Obs.: Amostras CG-02, GA-05, CG-29, CG-53 e CG-60 são mega* cristais do granito profiritico; a CG-53' um megacristal de encrave diorf́tico.

Os teores de ortoclásio encontrados pelas metodologias que usam esta reflexão situam-se na faixa de $86 \%$ a $93 \%$ (Tab. 4), com teor médio da ordem de $89 \%$. Mesmo considerando as evidências de os magacristais serem estruturalmente anômalos, verifica-se que não há diferenças muito significativas entre esses valores e os determinados por microssonda, sendo razoável admitir que os primeiros possam corresponder efetivamente às composições dos K-feldspatos estudados. Deve-se ressaltar que dos seis megacristais analisados por difração de raios- $X$, apenas a amostra $C G-60$ tem caráter fortemente anômalo ( $\overline{201}$ do difratograma - $\overline{201}$ do estado estrutural $=0,7^{\circ}$ de $2 \Theta$ ), enquanto as demais amostras mostram anomalias menos acentuadas da ordem de $0.35^{\circ}$ de $2 \theta$ (seriam cristais relativamente pouco anômalos). Os últimos poderiam ter seus teores de ortoclásio calculados pela reflexão 201 , ainda que seja aconselhável verificar os resultados por análises de microssonda.

Considerando os volumes das celas unitárias calculados a 


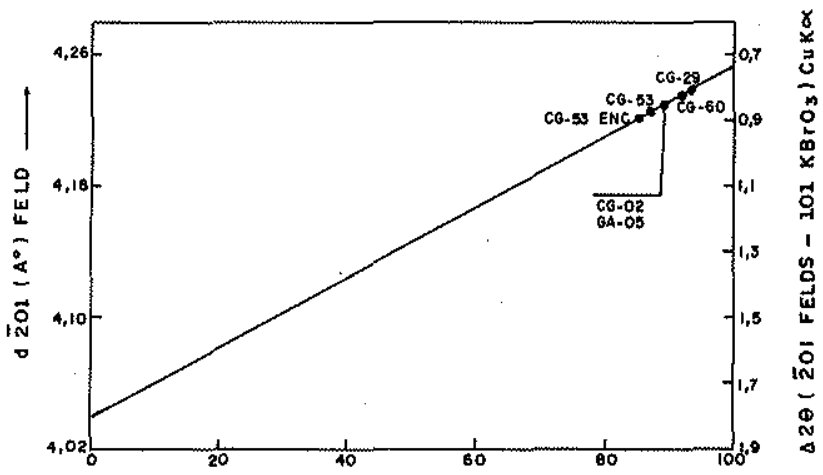

(\%) MOLECULAR DE Or (PARA CUK $\alpha$ )

Figura 11-Curva determinativa do teor de ortoclásio (Jones et al. 1969) com seis amostras analisadas por difraçäo de raios- $X$

partir dos parâmetros $a, b, c$, verifica-se que os teores de ortoclásio encontrados (Fig. 13) são mais baixos, variando de $82 \%$ a $91 \%$ e com media da ordem de aproximadamente $87 \%$. Cabe ressaltar que o valor de $82 \%$ é relativo à amostra CG-60, que tem caráter fortemente anômalo, sendo portanto menos confiável.

Tabela 4 - Teores de ortoclásio de seis megacristais de $K$ feldspato calculados pelos métodos de Jones et al. (1969), Wright (1968) e Wright \& Stewart (1968)

\begin{tabular}{l|c|c|c|c|c|c}
\hline Metodo Amostra & CG-02 & CG-05 & CG-29 & CG-53 & CG-60 & CG-53, \\
\hline Jones et al. & 89 & 89 & 93 & 88 & 92 & 86 \\
(1969) & 89 & 89 & 92 & 87 & 92 & 87 \\
Wright (1968) & 88 & 87 & 91 & 84 & 82 & 88 \\
Wright \& & 88 \\
Stewart (1968) & & & & & & \\
\hline
\end{tabular}

Obs.: Os teores de ortoclásio sāo em mol.\%. Amostras CG-02, GA-05, CG-29, CG-53 e CG-60 são do granito; a CG-53' é de megacristal de encrave diorítico

Diante dos resultados encontrados, é plenamente justificável admitir que o teor médio de ortoclásio dos $\mathrm{K}$-feldspatos estudados se situa na faixa de $87 \%$ a $89 \%$ e que não existem diferenças significativas entre os cristais analisados (desprezando-se os valores de amostras fortemente anômalas). Essas composiçöes são perfeitamente compatíveis com as fornecidas pela microssonda (teor médio da ordem de $91 \%$ ) e parecem aceitáveis, considerando as dificuldades inerentes ao uso de metodologias envolvendo análises por difração de raios- $X$.

ORIGEM DOS MEGACRISTAIS Os megacristais de K-feldspato em granitos, normalmente microclínios, em parte pertitizados, de forma euédrica e, por via de regra, zonados, podendo ou não apresentar texturas de cumulado e rapakivi, têm interpretações variadas quanto à sua origem. Vários autores - como Hibbard (1965, 1979), Higgins \& Kawachi (1977), Kawachi \& Sato (1978), Mehnert \& Busch (1981) e Vernon (1986) - têm interpretado os mesmos como fenocristais (origem magmática) enquanto Stone \& Austin (1961), Exley \& Stone (1964), Pitcher \& Berger (1972) e Souza (1985) interpretam os megacristais como porfiroblastos.

Os megacristais do granitoide de Monte das Gameleiras sāo euédricos, zonados, freqüentemente com inclusões orientadas e exibem por vezes texturas do tipo rapakivi, feiçōes estas muito pertinentes a fenocristais. Um outro aspecto a se destacar diz respeito às texturas ligadas à movimentação de Iíquido magmático. Como já foi referido, identifica-se no corpo uma foliação penetrativa, interpretađa como a conjugação dos efeitos da tectônica regional e o baloneamento causado pela colocação do plúton. Entretanto, é comum encontrarem-se localmente texturas de fluxo e entelhamento, que săo de caráter primário, associadas a movimentos do magma e podem preservar-se apesar de a rocha sofrer deformação no estado solido (Marre 1982, Bard 1980, Blumenfeld 1983).

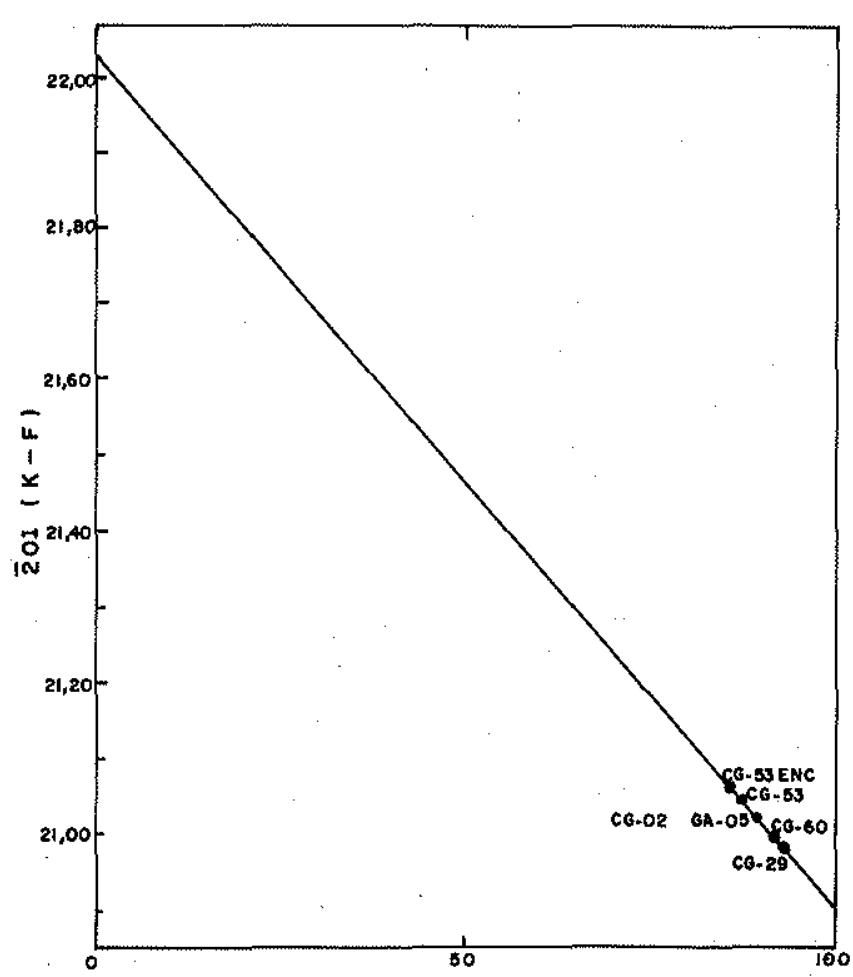

(\%) MOLECULAR DE Or (PARA CUKO)

Figura 12 - Curva determinativa do teor de ortoclásio (Wright 1968) com seis amostras analisadas por difração de raios-X

Observadas ao microscópio, as bordas irregulares dos cristais de K-feldspato, nos quais por vezes se desenvolve textura tipo mortar, indicam que no final da cristalizaçâo os megacristais tiveram suas formas influenciadas pela matriz da rocha. Esta feição sugere que os megacristais têm uma longa história de cristalização. Inicialmente, cresceram livres no liquido e adquiriram as feiçôes de zoneamento. Nos estagios finais de crescimento interagiram com a matriz. Outro aspecto a destacar é a presença constante de geminação simples segundo a lei de Carlsbad. Essa feição tem sido interpretada como própria de cristais magmáticos (Vernon 1986) por ser extremamente comum em fenocristais de $\mathrm{K}$-feldspato de rochas vulcânicas. Por outro lado, os grãos de microclínio da matriz apresentam geminação polissintética (albita e periclínio), resultando o típico padráo xadrez do microclínio. A presença de geminação polissintética em padrão xadrez é muito comum em $\mathrm{K}$-feldspato de rochas metamorficas interpretadas como porfiroblastos.

Outro aspecto textural típico desses megacristais é a grande quantidade de inclusões, por via de regra orientadas (notadamente de plagioclásio). A origem dessas inclusões orientadas é explicada por um processo de fixação (attachment) e incorporação de pequenos cristais na superfície euedral do $\mathrm{K}$ feldspàto em crescimento (mecanismo de synneusis de Vance 
1969). Os cristais de plagioclásio inclusos nos megacristais são menores que os da matriz e os teores de anortita dos primeiros săo em média mais altos. Se os megacristais de $\mathrm{K}$-feldspato fossem porfiroblastos, era de esperar que as inclusões de plagioclásio fossem de tamanho similar aos graõs de plagioclásio da matriz e que ambos apresentassem teores de anortita similares.

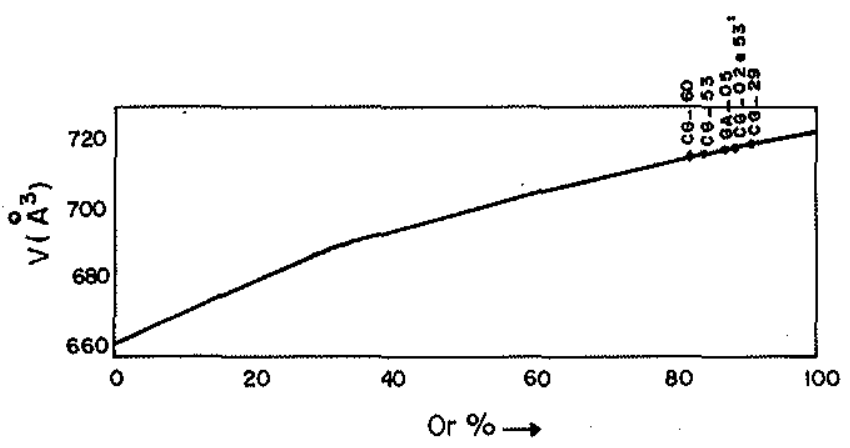

Figura 13 - Curva determinativa do teor de ortoclasio (Wright \& Stewart 1968) para seis amostras analisadas por difração de raios- $X$

Os teores de ortoclásio encontrados por difração de raios-X ficam na faixa de $87 \%$ a $89 \%$, năo havendo variaçőes significativas entre os vários cristais analisados do granito porfirítico, e mesmo entre estes e amostras de encraves dioríticos. Se isto por si só năo caracteriza a natureza magmática ou metamórfica do megacristal, evidencia pelo menos uma certa homogeneidade entre os cristais analisados, quer sejam do granito ou de encraves dioríticos. As análises de microssonda mostram tambem homogeneidade nos teores de ortoclásio (média de $91 \%$ de Or). As análises para bário (duas travessas feitas por microssonda) mostram uma zonação (ainda que não muito expressiva), em que os núcleos dos megacristais sáo enriquecidos neste elemento em relação às bordas. Sabe-se que cristais de feldspato potássico comprovadamente magmáticos (em rochas vulcânicas) apresentam zonação em bário com núcleos mais ricos em relaçáo às bordas. Essas tra vessas de bário mostram ainda que as regióes de contato megacristal/matriz têm teores similares àqueles dos núcleos dos megacristais. Esse enriquecimento pode estar ligado d infiltração hidrotermal tardia (Mehnert \& Busch 1981). Esse aporte de material caracteriza de certa forma um metassomatismo que não precisa estar ligado a eventos metamórficos sensu lato e não implica necessariamente serem os megacristais porfiroblastos.

Os megacristais que ocorrem nos encraves dioríticos apresentam texturas macro e microscópicas que em nada diferem das dos cristais do granito porfirítico. Diante de tais evidências 6 muito mais provável terem ambos uma mesma origem. Deve-se ressaltar ainda que apenas nos encraves dioríticos (microgranitoides no sentido de Vernon op. cit. e de Cantagrel 1984) são encontrados megacristais de $K$-feldspato e, quando se têm encraves das encaixantes (xenólitos), estes näo estão presentes. A presença de cristais de $\mathrm{K}$-feldspato nos encraves dioríticos pode ser explicada por um processo de penetração mecánica dos mesmos, no instante que os encraves ainda constituíam globulos de magma misturados ao material granítico (ja um cristal mush), havendo baixo contraste de viscosidade entre os dois materiais. Sá et al. (1986) defendem idéia semelhante para explicar a presença de megacristais de $\mathbf{K}$-feldspato em enclaves dioríticos no maciço de Acari (RN).

EVOLUÇÃO DOS MEGACRISTAIS Um modelo para a evolução dos megacristais do granitóide de Monte das Gameleiras envolve necessariamente uma longa história de cristalizaçāo. Ela deve ter começado após a cristalização das fases acessórias e máficas do granito bem como dos plagioclásios que se encontram como inclusões nos megacristais. Uma proposta de evolução pode tomar como base aquela adotada por Hibbard 1979) para K-feldspato do granodiorito de Sand Spring, os quais tem características texturais similares às dos megacristais de Monte das Gameleiras. Essa proposição envolve quatro estágios principais na evolução (Fig. 14):

1. Nucleação e crescimento de pequenos cristais de plagioclásio mais cálcico (a composição do líquido se situa no espaço de cristalização dos plagioclásios no diagrama $\mathrm{Qz}-\mathrm{Ab}-\mathrm{An}$ $\mathrm{Or}-\mathrm{H}_{2} \mathrm{O}$ ). Aqui haveria também a cristalização de zircão, apatita, opacos, titanita, biotita e homblenda, que aparecem como inclusōes nos megacristais.

2. Início da nucleação do K-feldspato indicando que a com posição do líquido atingiu a superfície cotética plagioclasiofeldspato potássico, ocorrendo então o seguinte: a. cristalização simultânea de plagioclásio e $\mathrm{K}$-feldspato; e b. alinhamento repetitivo de pequenos cristais de plagioclásio (os do estágio 1) no $\mathrm{K}$-feldspato em crescimento (mecanismo sunneusis de Vance 1969).

3. Início da cristalização do quartzo da matriz. indicando terse atingido linha cotética do sistema Qz-Ab-An-Or- $\mathrm{H}_{2} \mathrm{O}$.

4. Neste estágio tem-se já o desenvolvimento do núcleo e borda dos megacristais. Segue-se a formaçāo das coroas irregulares dos megacristais, que se dá simultaneamente com a consolidação final da matriz.
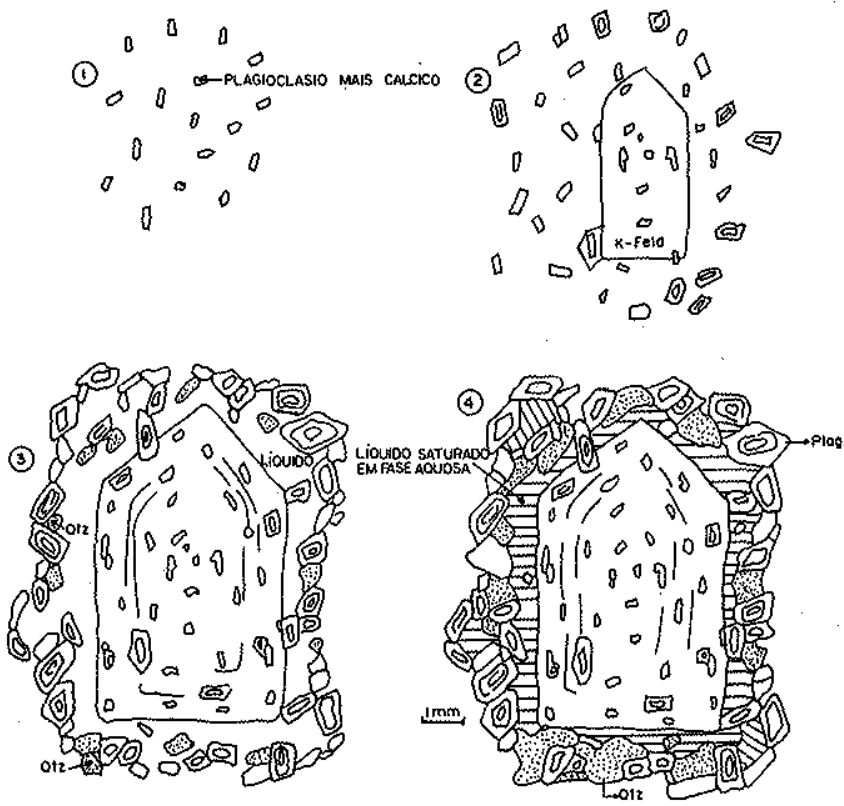

Figura 14 - Modelo esquemático da evoluçāo dos megacristais de K-feldspato (adaptado de Hibbard 1979)

CONCLUSÕES Diante das evidências texturais macro e microscópicas e composicionais (análises por microssonda e por difração de raios-X), optou-se por uma origem magmática (fenocristais) para os megacristais do granitóide de Monte das Gameleiras, tanto os do granito profirítico quanto os dos enclaves dioríticos. Os principais aspectos que corroboram esta hip6tese podem ser sumarizados da seguinte forma:

1. Os megacristais são essencialmente euedricos e zonados, não se observando qualquer índicio de recristalização.

2. São de cárater local, porém relativamente freqüentes, texturas associadas a processos nitidamente ígneo, como: texturas de fluxo, entelhamento (tuillage) cumulado e mesmo manteamento do tipo rapakivi. 
3. Zonação de bário, nos megacristais, similar à de fenocristais de rochas vulcânicas, a qual é obviamente magmática.

4. Teores médios de ortoclásio na faixa de aproximadamente $90 \%$, tanto para os megacristais do granito, quanto para os dos encraves dioríticos, sugerindo uma mesma origem para ambos (reforçada pela presença das mesmas texturas em seus megacristais).

5. Grande quantidade de inclusões de natureza variada, estando as mesmas orientadas, formadas sempre por cristais menores do que aqueles da mesma espécie que ocorre na matriz (notadamente no caso do plagioclásio).

Agradecimentos $\mathrm{O}$ autor agradece ao Conselho Nacio- nal do Desenvolvimento Científico e Tecnológico (CNPq) o financiamento dessa pesquisa; à Universidade Federal de Pernambuco (UFPE), pela realização das análises de difraçâo de raios-X em seus laboratórios; aos colegas Jaziel Martins Sá e Emanuel Ferraz Jardim de Sá, professores do Departamento de Geologia da Universidade Federal do Rio Grande do Norte, pela valiosa contribuição que deram durante as diversas fases desta pesquisa; e ao professor Roberto Dall'Agnoll, do Departamento de Geoquímica e Petrologia da Universidade Federal do Pará, por discussőes e sugestōes muito valiosas, e pela leitura final do texto.

\section{REFERÊNCIAS BIBLIOGRÁFICAS}

BARD, J.P. 1980 Microtextures des roches magmatiques et métamorfiques. Ed. Masson, Paris. 192p.

BLUMENFELD, P. 1983. Le tuillage des mégacristaux, un critère d'écoulement rotatinnel pour fluidalités des roches magmatiques. Aplication au granite de Barbey-Séroux (Vosges, France). Bull. Soc. Geol. France, 7, XXV(3):309-318.

BRITO-NEVES, B.B ; KAWASHITA, K.; PESSOA, D R. 1976. A posição estratigráfica do Complexo Caicó. In: SIMP. GEOL NORDESTE, 7, Fortaleza, 1976. Atas... Recife, SBG/№ v. 7 , p. 289-298,

CANTAGREL, J.M.; DIDIER, J.; GOURGAUD, A 1984. Magma mixing: origin of intermediate rocks and enclaves from volcanism to plutonism. Phy. Earth. Planet. Int., 35:63-76.

DEER, W.A ; HOWIE, R.A.; ZUSSMAN, J. 1976. An introduction to the rock-forming minerals. Londres. Longman, $528 \mathrm{p}$.

EXLEY, C.S. \& STONE, M. 1964. The granitic rocks of southwest England. Trans. R. Soc. Cornwall, 131:131-184.

GALINDO, A C. 1982. Estudo petrológico do corpo granítico de Monte das Gameleiras-RN/PB. Recife. 99p. (Tese de Mestrado).

GALINDO, A.C.; JARDIM DE SÁ, E.F.; LEGRAND, J.M.; SÁ, J.M.; MACEDO, M.H.F.; VITAL, H.; OLIVEIRA, M.L.; CASTRO, D.L. 1987. Projeto Granitos e Ortognaisses da Regiấo do Seridó (PADCT/FINEP). Rel. Tec. Final, Natal, 153p.

HIBBARD, M.J. 1965. Origin of some alkali-feldspar phenocrysts and their bearing on petrogenesis. Am. J.Sci., 263:245-261.

HIBBARD, M.J. 1979. Myrmekite as a marker between preaqueous and postaqueous phase saturation in granitic systems. Geol. Soc. Am. Bull., part I, 90:1047-1062.

HIGGINS, N.C. \& KAWACHI, Y. 1977. Microcline megacrysts from Green Lake granodiorite, eastern Fiordland, New Zealand. N.Z.J. Geol. Geophys., 20:273-286.

JONES, J.B.; NESBITT, R.W.; SLADE, P.C. 1969. The determination of the orthoclase content of homogenized alkali-feldspar using the 201 x-ray method. Miner. Mag., 37(288):489-496.

KAWACHI, Y, \& SATO, T, 1978. Orthoclase megacrysts in the Yakushima granite, southern Kyushu, Japan. Neus. Jahrb. Mineral. Abh., 132:136-152.

KERRICK, D.M. 1969. K-feldspar megacrysts from a porphyritic quartz monzonite, Central Sierra Nevada, California. Am. Mineral, 54:839-848.

MARRE, J. 1982. Méthodes d'analyse structurale des granitoides. Bur. Rech. GÉol. Min., 128pp. Man. \& Méthodes 3.
McMURRY, J. 1982. Petrology and Rb-Sr geochemistry of Monte das Gameleiras and Dona Inês plutons, northeaster, Brazil. Texas, $180 \mathrm{p}$. (MSc. Thesis, Univ. Texas at Austin).

MEHNERT, K.R. \& BUSCH, W. 1981. The Ba content of K-feldspar megacrysts in granites: a criterion for their formation. Neus. Jahrb. Mineral. Abh., 140:221-252.

PITCHER, W.S. \& BERGER, A.R. 1972. The geology of Donegal: a study of granite emplacement and unroofing. Wiley, New York, 435p.

SÁ, E.F. J. de; LEGRAND, J.M.; GALINDO, A.C.; HACKSPACHER, P.C.; SÁ, J.M. 1986. Granitogênese brasiliana no Serido: o maciço de Acari (RN), Rev. Bras. Geoc., 16(1):95-105.

SMITH, J.V. 1974. Feldspar minerals, vol. I e II. Berlim, Springer Verlang. $1317 \mathrm{p}$

SOUZA, Z.S. 1985. Os megacristais de K-feldspato do granito Dente de Cavalo de Acari (RN). Natal. Bol. DG-CCE/UFRN, 9:38-53.

STONE, M. \& AUSTIN, W.G.C. 1961. The metassomatic origin of potash feldspar megacrysts in the granites of southwest England. $J$. Geol., 69:464-472.

VANCE, J.A. 1969. On synneusis. Contrib. Mineral. Petrol., 24:7-29.

VERNON, R.H. 1986. K-feldspar megacrysts in granites-phenocrysts, not porphyroblasts. Earth Sci. Rev., 23:1-63.

WRIGHT, T.L. \& STEWART, D.B. 1968. X-ray and optical study of alkali feldspar: I. Determination of composition and structural state from refined until-cell parameters 2V. Am. Mineral., 53:38-86.

WRIGHT, T.L. 1968. X-ray and optical study of alkali feldspar: II. An $\mathrm{x}$-ray method for determining the composition and structural state from measurements of $2 \boldsymbol{\theta}$ for three reflection. Am. Mineral. 53:88-103.

Embora a natureza tenha dotado a espécie humana de grande riqueza, os recursos minerais são limitados e não podem ser renovados. Devemos pois fazer pleno uso deles e não desperdiçar um único grama. 